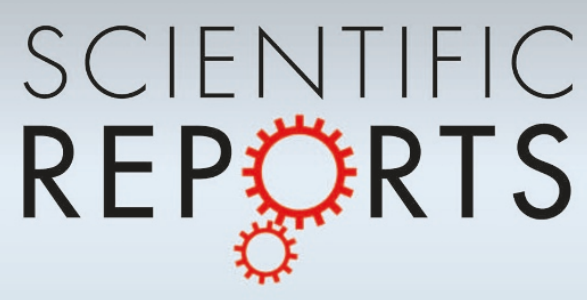

OPEN

SUBJECT AREAS:

APPLIED PHYSICS

OPTOELECTRONIC DEVICES AND

COMPONENTS

Received

28 October 2014

Accepted

22 January 2015

Published

17 February 2015

Correspondence and requests for materials should be addressed to

X.D.W.

(wangxiaodong@ ciomp.ac.cn)

\section{Design and fabrication of far ultraviolet filters based on $\pi$-multilayer technology in high-k materials}

Xiao-Dong Wang, Bo Chen, Hai-Feng Wang, Fei He, Xin Zheng, Ling-Ping He, Bin Chen, Shi-Jie Liu, Zhong-Xu Cui, Xiao-Hu Yang \& Yun-Peng Li

Changchun Institute of Optics, Fine Mechanics and Physics, Chinese Academy of Sciences, Changchun 130033, China.

Application of $\pi$-multilayer technology is extended to high extinction coefficient materials, which is introduced into metal-dielectric filter design. Metal materials often have high extinction coefficients in far ultraviolet (FUV) region, so optical thickness of metal materials should be smaller than that of the dielectric material. A broadband FUV filter of 9-layer non-periodic $\mathrm{Al} / \mathrm{MgF}_{2}$ multilayer was successfully designed and fabricated and it shows high reflectance in 140-180 nm, suppressed reflectance in 120-137 nm and 181$220 \mathrm{~nm}$.

$\mathrm{n}$ research for terrestrial aurora emission in FUV, narrowband and broadband filters are widely employed because unwanted line emission should be blocked to ensure high spectral purity in the working wavelength ${ }^{1-3}$.

Zukic and Torr did many pioneering jobs about FUV filters, and they proposed $\pi$-multilayer technology to design FUV filters ${ }^{4-6}$. FUV filters designed and fabricated by them were successfully utilized in ultraviolet imager for the International Solar-Terrestrial Physics mission ${ }^{1,2}$ and IMAGE satellite . $^{3}$

In optical thin film design for FUV spectral range, $\mathrm{LaF}_{3}, \mathrm{MgF}_{2}$ and $\mathrm{Al}$ are widely used due to their excellent optical properties. $\mathrm{MgF}_{2}$ is transparent at wavelength longer than $115 \mathrm{~nm}$; $\mathrm{Al}$ is the material with highest reflection in the vacuum ultraviolet down to $83 \mathrm{~nm}$. Al/ $\mathrm{MgF}_{2}$ and $\mathrm{LaF}_{3} / \mathrm{MgF}_{2}$ are two commonly employed material pairs in FUV wavelength range, and they are deposited by thermal evaporation method. $\mathrm{Al} / \mathrm{MgF} \mathrm{F}_{2}$ films were used as reflectance mirrors ${ }^{7-11}$, transmittance filters ${ }^{12-16}$ and reflectance filters ${ }^{17}$. In the beginning, $\mathrm{MgF}_{2} \mathrm{was}$ just used as a protective layer in order to avoid oxidation of $\mathrm{Al} . \mathrm{MgF}_{2}$-overcoated $\mathrm{Al}$ (two layers) mirrors have been extensively studied ${ }^{7-11}$. Malherbe deposited a double half-wave filter type of $\mathrm{Al} / \mathrm{MgF}_{2}$ for Lyman- $a$ line $(121.6 \mathrm{~nm})$ with a full width measured at half of the transmittance maximum (FWHM) of $9.0 \mathrm{~nm}^{12}$. Bates and Bradley prepared interference filters of $\mathrm{Al} / \mathrm{MgF}_{2}$ in the wavelength range of 170 to $240 \mathrm{~nm}$, and the peak transmission is $25 \%$ with a band pass $<30.0 \mathrm{~nm}^{13}$. Spiller fabricated $\mathrm{Al} / \mathrm{MgF}_{2}$ transmittance filters with different values of FWHM, and they ascribed the discrepancies between theoretical and experimental results to a coupling of light into the surface Plasmon of $\mathrm{Al}$ via a surface roughness of the $\mathrm{MgF}_{2}$ layers ${ }^{14}$. Transmittance filters of $\mathrm{Al} /$ $\mathrm{MgF}_{2}$ mentioned above were all designed based on the theory of Fabry-Perot interference filters. To authors' knowledge, reflectance filters of $\mathrm{Al} / \mathrm{MgF}_{2}$ were only studied by Osantowski and $\mathrm{Toft}^{17}$. They prepared broadband ultraviolet reflectance filters of $\mathrm{Al} / \mathrm{MgF}_{2}$ with peak reflectance at $185.0,230.0$, and $260.0 \mathrm{~nm}^{17}$, and the FWHM can be up to be $120 \mathrm{~nm}$. However, the detailed design was not provided. Reflectance filters made of $\mathrm{Al} / \mathrm{MgF}_{2}$ have larger values of FWHM as compared to $\mathrm{LaF}_{3} / \mathrm{MgF}_{2} 4,17$.

Besides filters in FUV deposited by physical vapor deposition method (thermal evaporation, magnetron sputtering), recently, some ultraviolet mirrors deposited by sol-gel were reported ${ }^{18-20} \cdot \mathrm{ZrO}_{2} / \mathrm{SiO}_{2}$ nanoparticle films were prepared to selectively block ultraviolet wavelength ranges based on interference effects, and they can be self-standing, flexible, transferable if a polymer was infiltrated in the pore network of films ${ }^{18}$. Fe ${ }^{3+} \mathrm{doped} \mathrm{Mg} / \mathrm{Al}$ coatings were prepared by a facile solvothermal method, and their ultraviolet-absorption was efficiently tuned by $\mathrm{Fe}^{3+}$ to cover the entire ultraviolet range ${ }^{19}$. Perforated multilayers were generated by collective osmotic shock to reflect selectively ultraviolet radiation ${ }^{20}$. Films prepared by sol-gel demonstrate some better properties as compared to physical vapor deposition. However, to our knowledge, there are no multilayers prepared by sol-gel at targeted wavelength of less than $200 \mathrm{~nm}$, and few optical thin films prepared by sol-gel were employed in space exploration. Surface roughness of films has a great influence on optical performance of multilayers at targeted wavelength of less than $200 \mathrm{~nm}$. Optical coatings in the space environment are exposed to high energy particulate, 
electromagnetic radiations, and large temperature excursions ${ }^{21}$, and they must have a stable structure. Great improvements in optical coatings deposited by sol-gel should be made, such as layer thickness control, surface roughness, and structural stability.

A special multilayer mirror was employed in the FUV Wideband Imaging Camera installed in IMAGE satellite, and it has working wavelength region from 140-190 $\mathrm{nm}$, also has low reflectance in the visible and near ultraviolet region ${ }^{3}$. However, they did not tell us what the specific material pair they used was. Similar broadband filters are also in great demand in an Imager installed in FengYun III, which will be launched in 2015. we want to yield spectra emission of $\mathrm{N}_{2}$ Lyman-Birge-Hopfield Bands (140-180 nm), and suppress the two oxygen emissions at 130.4 and $135.6 \mathrm{~nm}$, hydrogen Lyman- $\alpha$ line at $121.6 \mathrm{~nm}$, and contamination signals from the wavelength region longer than $180 \mathrm{~nm}$ by virtue of this filter ${ }^{2}$. In this paper, a broadband filter of non-periodic $\mathrm{Al} / \mathrm{MgF}_{2}$ was designed based on modified $\pi$-multilayer technology and fabricated.

\section{Theory and design}

$\pi$-multilayer is defined as one has a periodic optical thickness of a half of reference wavelength, which can be described by equation $(1)^{4}$ :

$$
H+L=0.5 \lambda_{r}
$$

where $H$ and $L$ denote optical thickness of high- and low-index film materials, and $\lambda_{\mathrm{r}}$ is the reference wavelength. If $H=L=0.25 \lambda_{\mathrm{r}}$, that is a traditional quarter-wave $(\mathrm{QW})$ multilayer. In FUV wavelength region, $\mathrm{BaF}_{2}$ and $\mathrm{LaF}_{3}$ are often employed to be high-index film materials, and $\mathrm{MgF}_{2}$ low-index one. The extinction coefficients of $\mathrm{BaF}_{2}$ and $\mathrm{LaF}_{3}$ are 100 times larger than that of $\mathrm{MgF}_{2}$. Zukic and Torr believed that if $H / L<1$, absorption will be lower, hence filters with higher reflectance and a narrower FWHM can be obtained. The above description of $\pi$-multilayer technology is just a brief introduction, and the details can be found in Ref. 4.

It should be noted that Zukic and Torr just studied multi-dielectric components for the FUV, and $\pi$-multilayer technology can be modified to design metal-dielectric multilayer. In other words, Zukic and Torr just discussed the application of $\pi$-multilayer technology in low-absorption materials, and we want to extend the application of $\pi$-multilayer technology to high-absorption materials. Here, we choose $\mathrm{Al} / \mathrm{MgF}_{2}$ to be a candidate material pair of a multilayer because besides $\mathrm{LaF}_{3} / \mathrm{MgF}_{2}{ }^{4,22}, \mathrm{Al} / \mathrm{MgF}_{2}$ is another commonly used one in FUV region ${ }^{7-17}$.

In this material pair, $\mathrm{MgF}_{2}$ is high-index material, and has a magnitude of $10^{-4}$ for extinction coefficient ${ }^{5}$; $\mathrm{Al}$ is low-index material, and has a magnitude of $10^{\circ}$ for extinction coefficient ${ }^{23}$; fused silica is substrate material (thickness of $1.5 \mathrm{~mm}$ ). The optical constant of $\mathrm{MgF}_{2}$ was derived from characterization of reflectance and transmittance of deposited 160-nm single $\mathrm{MgF}_{2}$ layer (by OptiLayer software ${ }^{24}$ ), and the optical constants of $\mathrm{Al}$ and fused silica substrate are cited from Center for Nanolithography Research, Rochester Institute of Technology. Our aim is to obtain high reflectance in the wavelength range of $140 \mathrm{~nm}$ to $180 \mathrm{~nm}$, meanwhile, suppressed reflectance in 120-137 nm and 181-220 nm. As we all know, QW $\mathrm{Al} / \mathrm{MgF}_{2}$ multilayer has enough high reflectance due to high reflectance of Al layer (Figure 1). Al film has lower refractive index with a magnitude of $10^{-2}$, and larger extinction coefficient with a magnitude of $10^{\circ}$. The reflectance of $\mathrm{Al}$ film can be calculated by equation (2) (the incident medium is air):

$$
R=\frac{(1-n)^{2}+k^{2}}{(1+n)^{2}+k^{2}}
$$

where $n$ is refractive index, $k$ is extinction coefficient. The reflectance of $\mathrm{Al}$ film is dependent on $k$ because of $k \gg n$ for $\mathrm{Al}$ film. Al film still has high reflectance even if the optical thickness of Al layer is largely less than QW. This can be interpreted by a general rule that if any material gets to be a very good absorber at any frequency, the waves are strongly reflected at the surface and very little gets inside to be absorbed. More details about this rule can be found in Ref. 25 .

Now our problem is not to try to enhance reflectance, but to suppress the reflectance in $120-137 \mathrm{~nm}$ and $181-220 \mathrm{~nm}$ at the expense of a slight drop of reflectance in 140-180 nm. In other words, we want to design a broadband filter instead of a reflectance mirror. Thus, inversely, we should keep $H / L>1$. Figure 1 shows theoretical reflectance of 9-layer periodic $\mathrm{Al} / \mathrm{MgF}_{2}$ multilayer for $\mathrm{H} / \mathrm{L}$ $=1,132$, the reference wavelength is $160 \mathrm{~nm}$, and the incident angle is $22^{\circ}$. For $H / L=1$, that is QW multilayer, it has reflectance of 74$83 \%$ in $120-220 \mathrm{~nm}$. For $H / L=132$, it corresponds to optical thick-

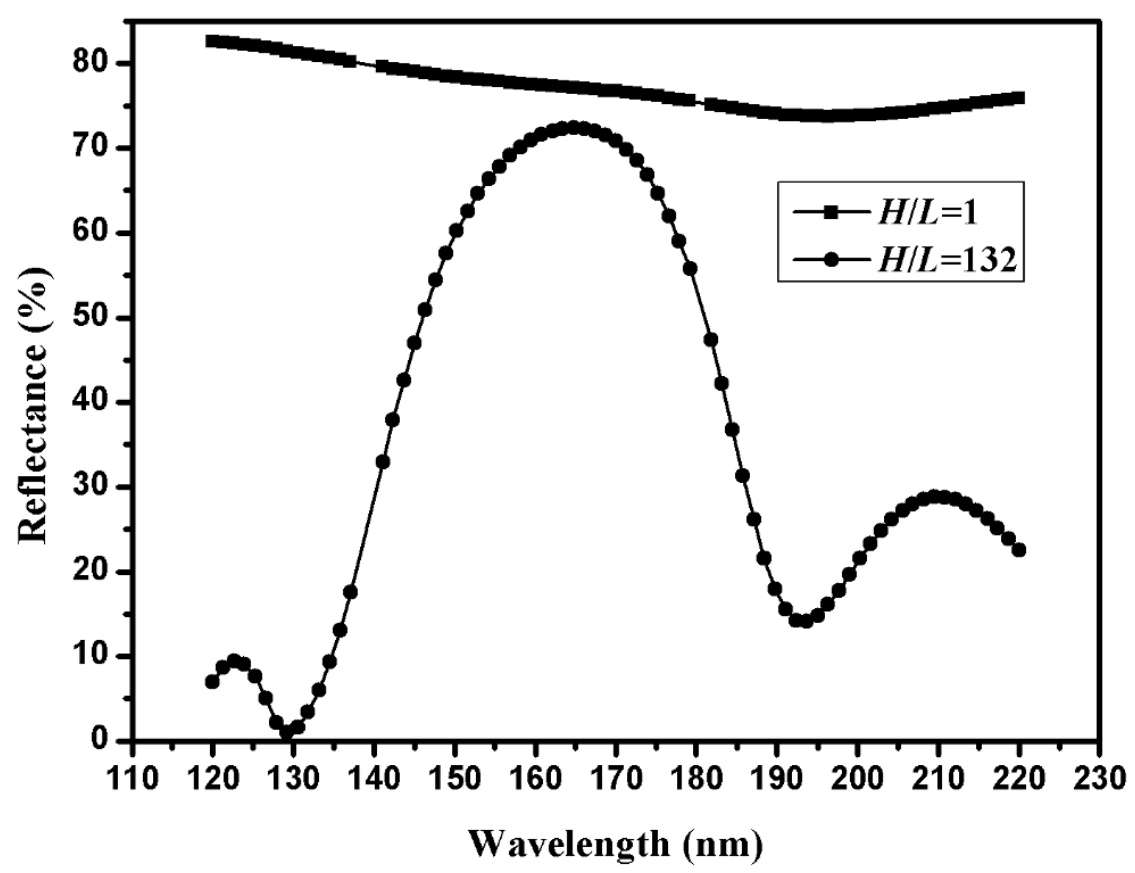

Figure 1 Theoretical reflectance of 9-layer periodic $\mathrm{Al} / \mathrm{MgF}_{2}$ multilayer with an incident angle of $22^{\circ}$ for $H / L=1,132$. 

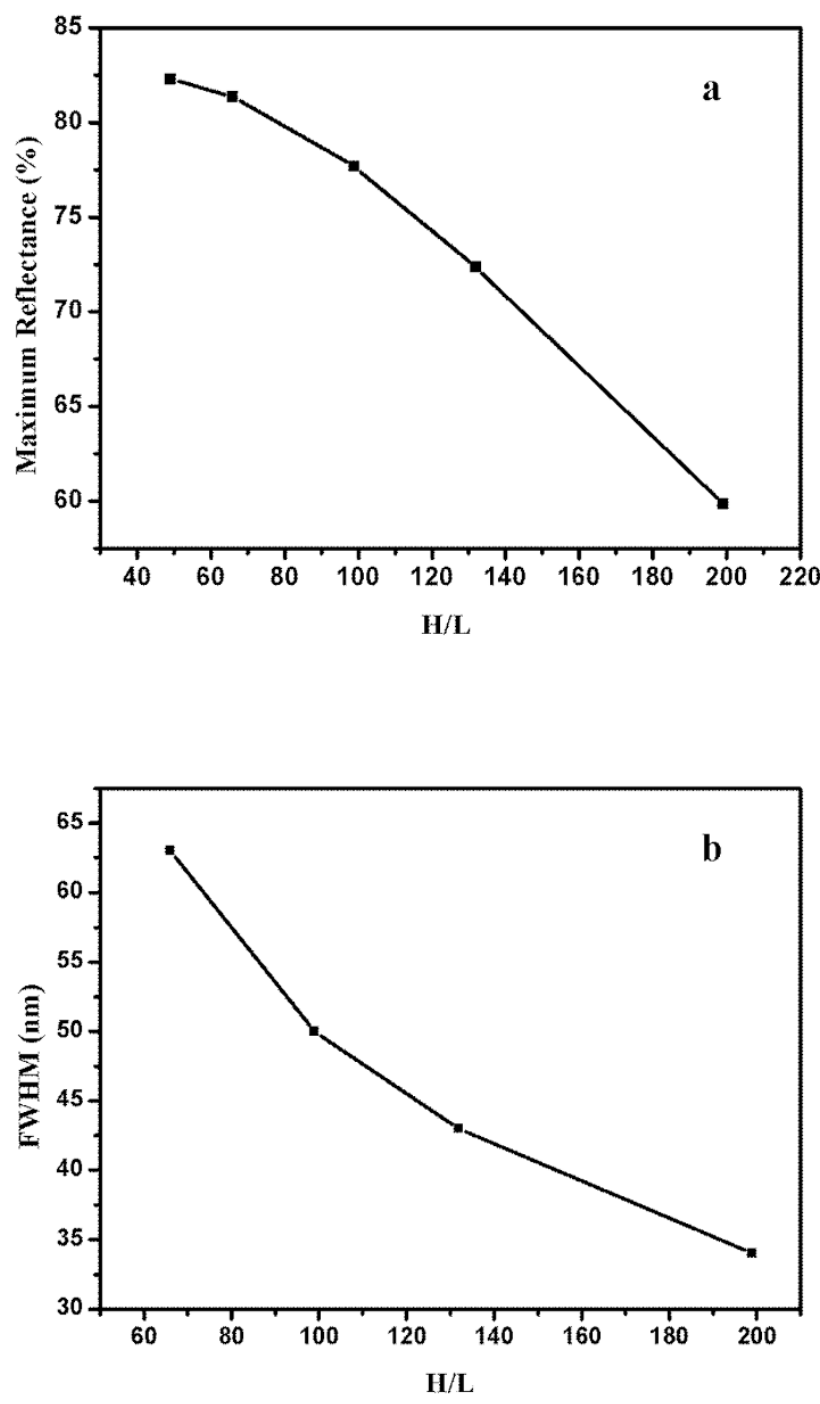

Figure 2 | Calculated maximum reflectance (a) and FWHM (b) of 9-layer periodic $\mathrm{Al} / \mathrm{MgF}_{2}$ multilayer as a function of the $H / L$ ratio. nesses of high- and low-index film materials:

$$
\begin{aligned}
& H=n_{H} d_{H}=1.985 \lambda_{r} \\
& L=n_{L} d_{L}=0.015 \lambda_{r}
\end{aligned}
$$

The 9-layer stack with this ratio has a filter feature, and the FWHM is $43 \mathrm{~nm}$.

Figure 2 demonstrates calculated maximum reflectance and FWHM of 9-layer $\mathrm{Al} / \mathrm{MgF}_{2}$ multilayer as a function of the $H / L$ ratio. The maximum reflectance and FWHM decrease with increasing of $H / L$ ratio. The ratio of $H / L$ can not be too big, and we must consider the thinnest feasible Al layer. As shown in Figure 2, according to our aim, 9-layer $\mathrm{Al} / \mathrm{MgF}_{2}$ multilayer with $H / L=132$ seems to be the most feasible choice. However, the suppression feature in longer wavelength is not so good. Thus, we use Refinement function $\left(\right.$ OptiLayer software $\left.^{24}\right)$ to optimize the performance of 9-layer periodic $\mathrm{Al} / \mathrm{MgF}_{2}$ broadband filter for $H / L=132$. The refined, calculated result is shown in Figure 3, the FWHM is $40 \mathrm{~nm}$, and this nonperiodic filter has relatively better reflectance suppression in 120$137 \mathrm{~nm}$ and 181-220 nm, which meets our requirements. The optical thickness of the filter is $402.1 \mathrm{~nm}$. The physical thickness of Al layer varies from $4.0-10.0 \mathrm{~nm}$.

\section{Results}

Figure 4 shows reflectance of fabricated 9-layer non-periodic Al/ $\mathrm{MgF}_{2}$ multilayer, for comparison, and the design curve is also provided. High reflectance in the working wavelength region and better reflectance suppression in unwanted wavelength region are obtained. However, obvious discrepancies between the experiment and theoretical design still exist. This disagreement can be ascribed to film inhomogeneity, surface roughness, and thickness control error, which are not taken into account in theoretical calculation.

Figure 5 demonstrates a reflectance curve of deposited 9-layer non-periodic $\mathrm{Al} / \mathrm{MgF}_{2}$ multilayer with an incident angle of $8^{\circ}$. The reflectance of deposited broadband filter in 120-125 nm was measured by our own developed spectrophotometer. The reflectance of deposited broadband filter in 126-380 nm was measured by McPherson VUVaS ultraviolet spectrophotometer, and the reflectance in 381-760 nm was characterized by Lambda 950 UV/VIS/ NIR Spectrophotometer. As shown in Figure 5, this broadband filter

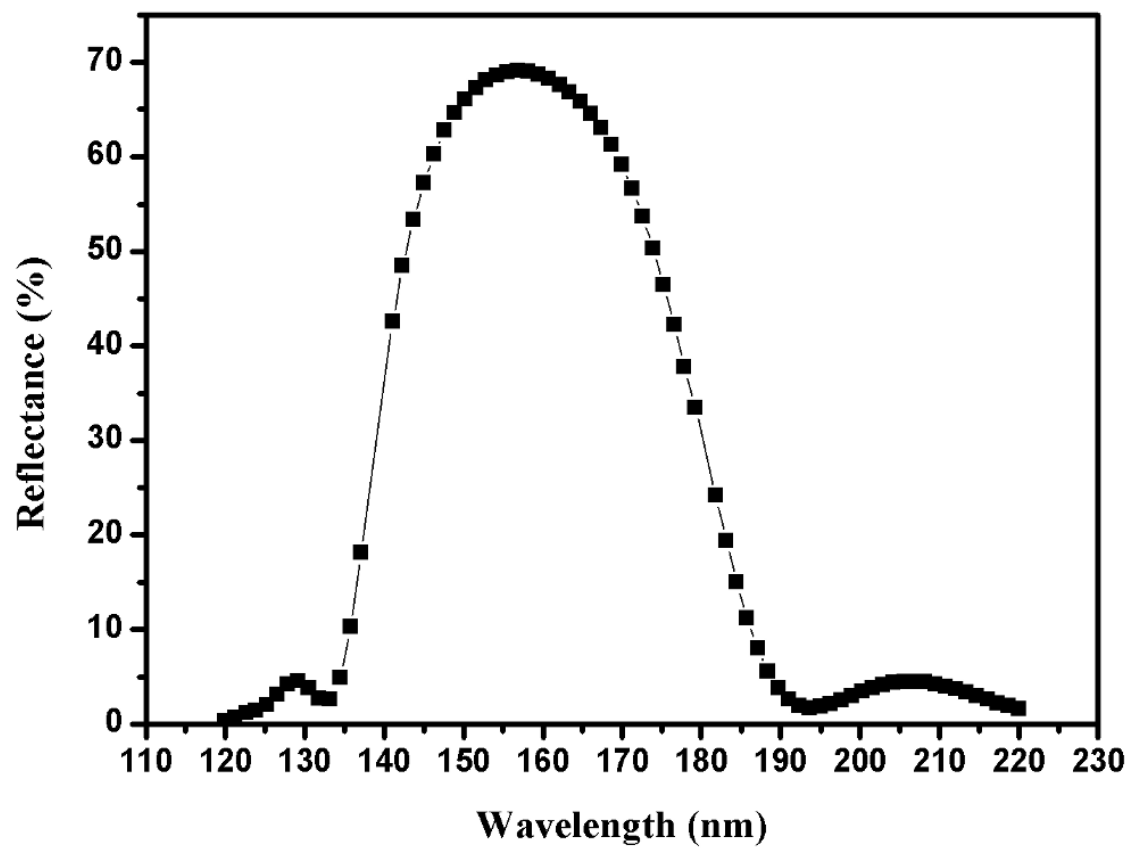

Figure $3 \mid$ The refined, calculated result of 9-layer non-periodic $\mathrm{Al} / \mathrm{MgF}_{2}$ multilayer with an incident angle of $22^{\circ}$. 


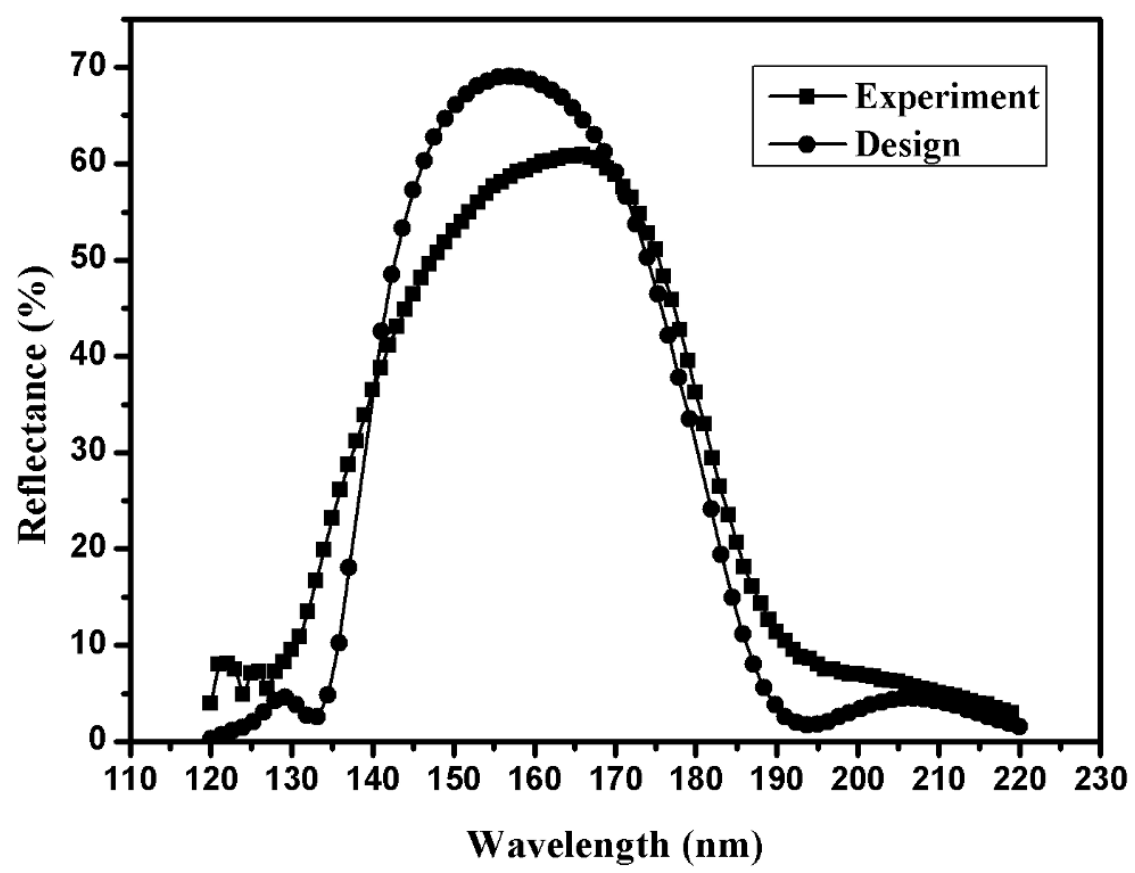

Figure $4 \mid$ Reflectance curves of designed and fabricated 9-layer non-periodic $\mathrm{Al} / \mathrm{MgF}_{2}$ multilayer with an incident angle of $22^{\circ}$.

also has a good reflectance blocking of visible light, and the only drawback is high reflectance of $32 \%$ centered at $321 \mathrm{~nm}$.

Figure 6 shows reflectance curves of as-deposited and two-month aged of 9-layer non-periodic $\mathrm{Al} / \mathrm{MgF}_{2}$ multilayer, and the incident angle is $22^{\circ}$. The deposited sample was kept in a desiccator at room temperature. After two months, reflectance curve shifts toward longer wavelength, and there is a slight drop of maximum reflectance. Similar phenomenon of $\mathrm{Al} / \mathrm{MgF}_{2}$ transmittance filters was reported by Bates and Bradley ${ }^{13}$. This change may be explained by absorption of water in $\mathrm{MgF}_{2}$ layer ${ }^{29}$ and slow continuing oxidation of $\mathrm{Al} \mathrm{films}{ }^{13}$. When $\mathrm{Al}$ is deposited, little oxygen still exists due to gas release from deposition materials although the base pressure of chamber is $1.3 \times 10^{-4} \mathrm{~Pa}$, and reacts with $\mathrm{Al}$ films. Oxidation of
$\mathrm{Al}$ film is a long process, and it can continue after deposition of $\mathrm{Al}$ films ${ }^{26-28}$. Moreover, formed oxide layers undergo gradual structural transformation from amorphous phase to crystalline one $e^{28}$. In addition, it is generally accepted that $\mathrm{MgF}_{2}$ film should be deposited at a high substrate temperature ${ }^{29}$, and $\mathrm{Al}$ film should be prepared at room temperature. In order to obtain high reflectance of filters, we do not make the substrate heated. Thus, our $\mathrm{MgF}_{2}$ layer is not dense enough, and they maybe undergo slight structural change after deposition. The reason for the shift of reflectance curve is under further investigation.

In Summary, we extend $\pi$-multilayer technology to design broadband FUV filters with high- $k$ materials, and discuss optical properties of 9-layer $\mathrm{Al} / \mathrm{MgF}_{2}$ multilayer for $H / L>1$ instead of $H / L<1$.

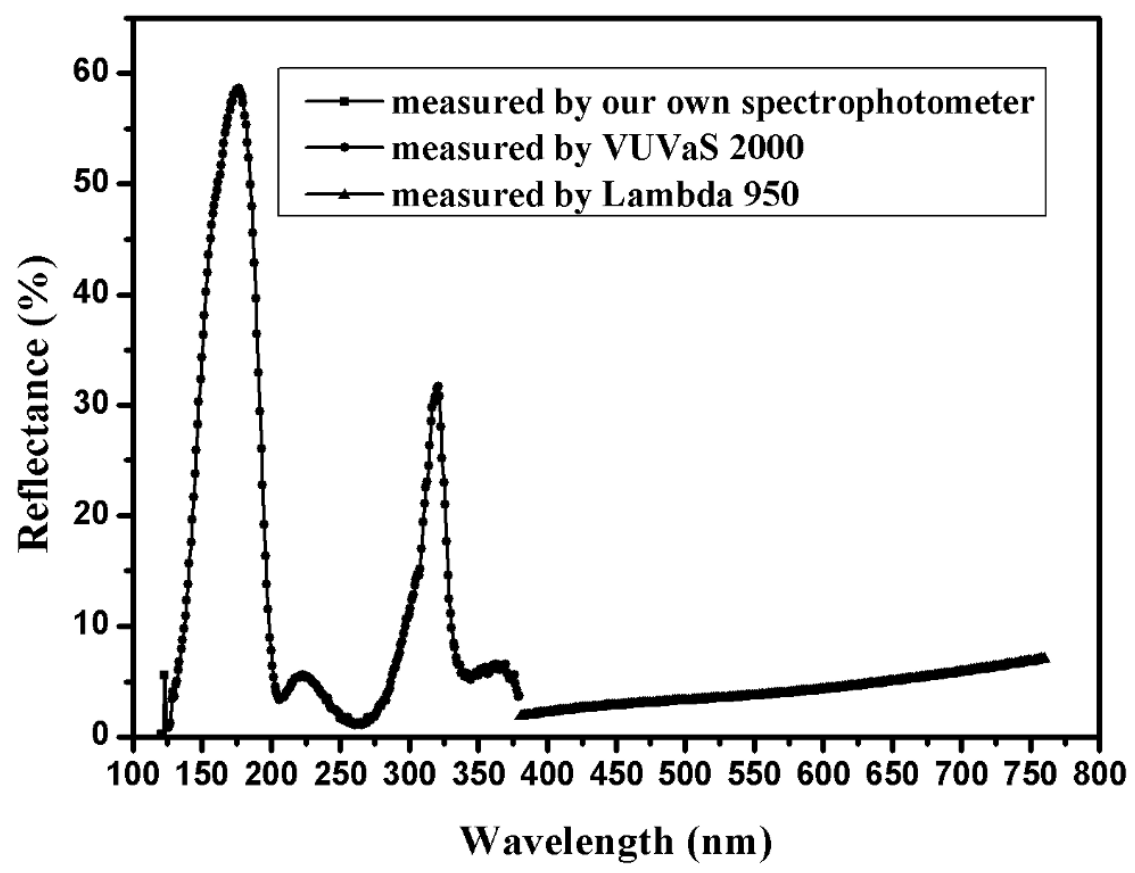

Figure $5 \mid$ Reflectance curves of fabricated 9-layer non-periodic $\mathrm{Al} / \mathrm{MgF}_{2}$ multilayer with an incident angle of $8^{\circ}$. 


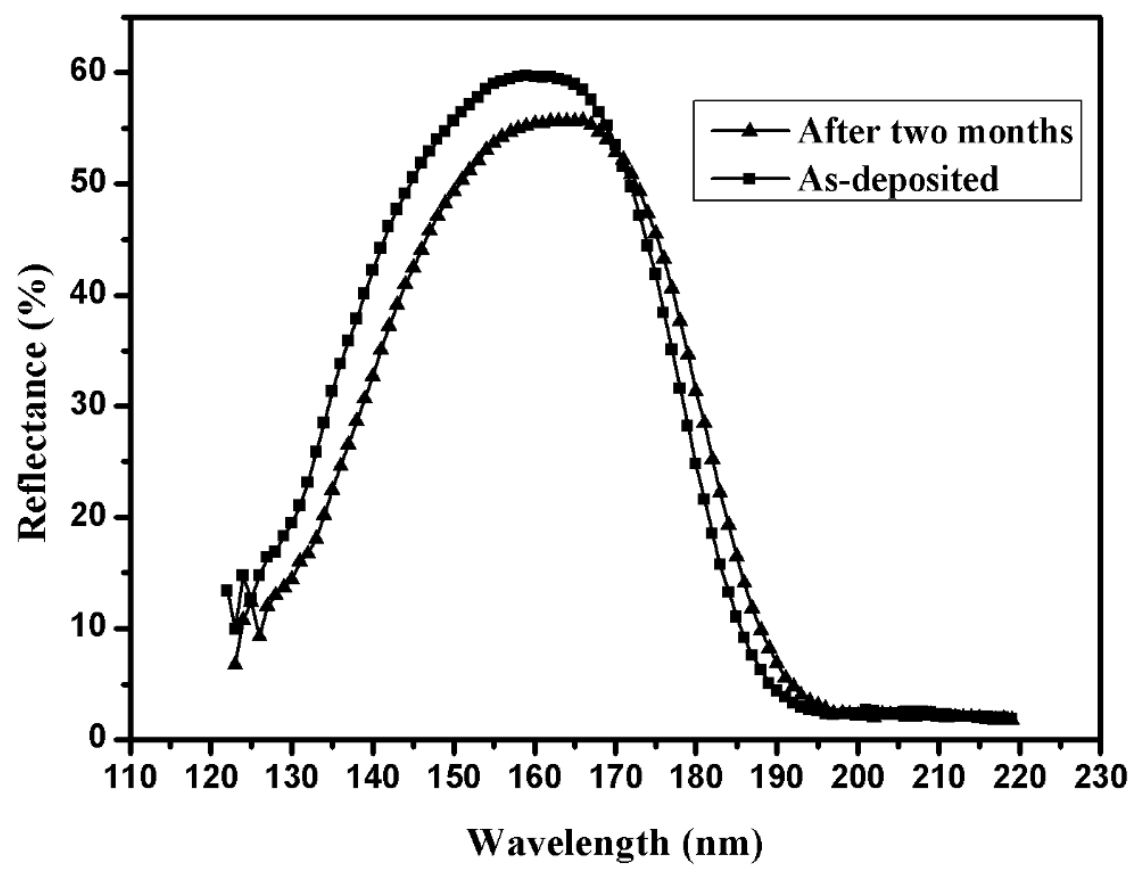

Figure 6 Reflectance curves of as-deposited and two-month aged of 9-layer non-periodic $\mathrm{Al} / \mathrm{MgF}_{2}$ multilayer with an incident angle of $22^{\circ}$.

A 9-layer non-periodic $\mathrm{Al} / \mathrm{MgF}_{2}$ broadband filter was successfully designed and fabricated to meet our requirements. This extended $\pi$ multilayer theory is a powerful, promising technology to be employed in designing FUV filters made of metal-dielectric material pairs.

$\pi$-multilayer technology is a method to design filters proposed by Zukic and Torr, and they just demonstrated the discussion for the case of low- $k$ materials. Here, we provide its application for the case of high- $k$ materials. Thus, applications of $\pi$-multilayer technology are extensively extended, and filters with specific reflectance and FWHM can be hopefully designed by tuning $H / L$ ratio.

\section{Methods}

The used $\mathrm{Al}$ and $\mathrm{MgF}_{2}$ have a purity of $99.99 \%$. The depositions were made in an electron beam evaporation vacuum system. The base pressure was $1.3 \times 10^{-4} \mathrm{~Pa}$. Al and $\mathrm{MgF}_{2}$ in copper crucible were evaporated by electron beam. The voltage of electron gun was fixed to be $10 \mathrm{kV}$, the thickness of films and deposition rate were controlled by a quartz crystal (IC6, Inficon Company). The distance between the source and substrate is $50 \mathrm{~cm}$, the distance between the quartz crystal and source is $45 \mathrm{~cm}$. The deposition rate of $\mathrm{Al}$ and $\mathrm{MgF}_{2}$ was $0.3 \mathrm{~nm} / \mathrm{s}$. The substrate was not heated.

The reflectance and transmittance of films in the wavelength range of 120-125 nm were measured by our own developed spectrophotometer with a step of $1 \mathrm{~nm}$, and the base pressure was $2 \times 10^{-4} \mathrm{~Pa}$. The reflectance and transmittance of films in the wavelength range of 126-380 $\mathrm{nm}$ were measured by McPherson VUVaS ultraviolet spectrophotometer with a step of $1 \mathrm{~nm}$, and the base pressure was $4 \times 10^{-3} \mathrm{~Pa}$. Vacuum ultraviolet line can be strongly absorbed by atmospheric oxygen, so the FUV spectral measurements must be performed at low pressure. The reflectance of films in the wavelength range of 381-760 $\mathrm{nm}$ was characterized by Lambda 950 UV/VIS/NIR Spectrophotometer with a step of $1 \mathrm{~nm}$ in ambient atmosphere.

1. Zukic, M., Torr, D. G., Kim, J., Spann, J. F. \& Torr, M. R. Filters for the International Solar Terrestrial Physics Mission far-ultraviolet imager. Opt. Eng. 32, 3069-3074 (1993).

2. Torr, M. R. et al. A far ultraviolet imager for the International Solar-Terrestrial Physics Mission. Space Sci. Rev. 71, 329-383 (1995).

3. Mende, S. B. et al. Far ultraviolet imaging from the image spacecraft. 2. wideband FUV imaging. Space Sci. Rev. 91, 271-285 (2000).

4. Zukic, M. \& Torr, D. G. Multiple reflectors as narrow-band and broadband vacuum ultraviolet filters. Appl. Opt. 31, 1588-1596 (1992).

5. Zukic, M., Torr, D. G., Spann, J. F. \& Torr, M. R. Vacuum ultraviolet thin films. 1: optical constants of $\mathrm{BaF}_{2}, \mathrm{CaF}_{2}, \mathrm{LaF}_{3}, \mathrm{MgF}_{2}, \mathrm{Al}_{2} \mathrm{O}_{3}, \mathrm{HfO}_{2}$ and $\mathrm{SiO}_{2}$. Appl. Opt. 29, 4284-4292 (1990).

6. Zukic, M., Torr, D. G., Spann, J. F. \& Torr, M. R. Vacuum ultraviolet thin films. 2: vacuum ultraviolet all-dielectric narrowband filters. Appl. Opt. 29, 4293-302 (1990).
7. Canfield, L. R., Hass, G. \& Waylonis, J. E. Further studies on $\mathrm{MgF}_{2}$-overcoated aluminum mirrors with highest reflectance in the vacuum ultraviolet. Appl. Opt. 5, 45-50 (1966).

8. Hutcheson, E. T., Hass, G. \& Cox, J. T. Effect of deposition rate and substrate temperature on the vacuum ultraviolet reflectance of $\mathrm{MgF}_{2}$ - and $\mathrm{LiF}$-overcoated aluminum mirrors. Appl. Opt. 11, 2245-2248 (1972).

9. Yang, M., Gatto, A. \& Kaiser, N. Highly reflecting aluminum-protected optical coatings for the vacuum-ultraviolet spectral range. Appl. Opt. 45, 178-183 (2006)

10. Fernández-Perea, M., Larruquert, J. I., Aznárez, J. A., Pons, A. \& Méndez, J. A. Vacuum ultraviolet coatings of $\mathrm{Al}$ protected with $\mathrm{MgF}_{2}$ prepared both by ionbeam sputtering and by evaporation. Appl. Opt. 46, 4871-4878 (2007).

11. Wilbrandt, S. et al. N. Protected and enhanced aluminum mirrors for the VUV. Appl. Opt. 53, A125-A130 (2014).

12. Malherbe, A. Interference filters for the far ultraviolet. Appl. Opt. 13, 1275-1276 (1974).

13. Bates, B. \& Bradley, D. J. Interference filters for the far ultraviolet (1700 A to 2400 Å). Appl. Opt. 5, 971-975 (1966).

14. Spiller, E. Interference filters for the ultraviolet and the surface plasmon of aluminum. Appl. Opt. 13, 1209-1215 (1974).

15. Fairchild, E. T. Interference filters for the VUV (1200-1900 A). Appl. Opt. 12, 2240-2241 (1973).

16. Larruquert, J. L. et al. GOLD's coating and testing facilities for ISSIS-WSO. Astrophys. Space Sci. 335, 305 (2011).

17. Osantowski, J. F. \& Toft, A. R. Broadband ultraviolet reflectance filters for space applications. Appl. Opt. 12, 1114-1115 (1973).

18. Smirnov, J. R. C., Calvo, M. E. \& Míguez, H. Selective UV reflecting mirrors based on nanoparticle multilayers. Adv. Funct. Mater. 23, 2805-2811 (2013).

19. Wang, X., Zhou, S. \& Wu, L. Fabrication of $\mathrm{Fe}^{3+}$ doped $\mathrm{Mg} / \mathrm{Al}$ layered double hydroxides and their application in UV light-shielding coatings. J. Mater. Chem. C 2, 5752-5758 (2014).

20. Zavala-Rivera, P. et al. Collective osmotic shock in ordered materials. Nat. Mater. 11, 53-57 (2012).

21. Piegari, A. \& Flory, F. Optical thin films and coatings: from materials to applications First edition. 789-809 (Woodhead Publishing, 2013).

22. Malherbe, A. Multidielectric components for the far ultraviolet. Appl. Opt. 13, 1276-1276 (1974).

23. Rakić, A. D. Algorithm for the determination of intrinsic optical constants of metal films: application to aluminum. Appl. Opt. 34, 4755-4767 (1995).

24. Tikhonravov, A. V. \& Trubetskov, M. K. OptiLayer thin film software. Available at: http://www.optilayer.com. (Accessed: 23th October 2014).

25. Feynman, R. P., Leighton, R. B. \& Sands, M. Feynman lectures on physics, vol. IIthe new millennium edition: mainly electromagnetism and matter. (Basic Books, New York, 2011).

26. Fery, C., Bailey, W. E., Yamada, K. \& Wang, S. X. Study of natural oxidation of ultra-thin aluminum layers with in-situ resistance measurement. MRS Proceedings 569, 185 (1999).

27. Baran, J. D., Grönbeck, H. \& Hellman, A. Mechanism for limiting thickness of thin oxide films on aluminum. Phys. Rev. lett. 112, 146103 (2014). 
28. Jeurgens, L. P. H., Sloof, W. G., Tichelaar, F. D. \& Mittmeijer, E. J. Growth kinetics and mechanisms of aluminum-oxide films formed by thermal oxidation of aluminum. J. Appl. Phys. 92, 1649 (2002).

29. Sun, J., Shao, J., Yi, K. \& Zhang, W. Effects of substrate temperatures on the characterization of magnesium fluoride thin films in deep-ultraviolet region. Appl. Opt. 53, 1298-1305 (2014).

\section{Acknowledgments}

This work is supported by the National Natural Science Foundation of China (grant No. 10878004). We thank Professor Alexander Tikhonravov from Moscow State University for fruitful discussions of characterization of optical constant of $\mathrm{MgF}_{2}$ films.

\section{Author contributions}

X.D.W. designed research, analyzed data and wrote the paper, Bi.C. and H.F.W. wrote the main manuscript text, X.Z., L.P.H., Bo.C., S.J.L., Z.X.C., X.H.Y. and Y.P.L. prepared figures 1-6. F.H. revised the literature. All authors reviewed the manuscript.

\section{Additional information}

Competing financial interests: The authors declare no competing financial interests.

How to cite this article: Wang, X.-D. et al. Design and fabrication of far ultraviolet filters based on $\pi$-multilayer technology in high- $k$ materials. Sci. Rep. 5, 8503; DOI:10.1038/ srep08503 (2015).

(c) (i)

This work is licensed under a Creative Commons Attribution 4.0 International License. The images or other third party material in this article are included in the article's Creative Commons license, unless indicated otherwise in the credit line; if the material is not included under the Creative Commons license, users will need to obtain permission from the license holder in order to reproduce the material. To view a copy of this license, visit http://creativecommons.org/licenses/by/4.0/ 